\section{The public health and economic consequences of unintended pregnancies in South Africa}

\author{
Hoa H. Le, ${ }^{1}$ Mark P. Connolly, ${ }^{1,2}$ \\ Jingbo $\mathrm{Yu}^{3}{ }^{3}$ Yacob Pinchevsky, ${ }^{4}$ \\ Petrus S. Steyn ${ }^{5}$ \\ 'Department of Pharmacy, University of \\ Groningen, The Netherlands; \\ ${ }^{2}$ Global Market Access Solutions, \\ Mooresville, NC, USA; \\ ${ }^{3}$ Merck \& Co., Whitehouse Station, NJ, \\ USA; \\ ${ }^{4}$ MSD (Pty) Ltd., South Africa; \\ ${ }^{5}$ Department of Obstetrics and \\ Gynaecology, University of Cape Town, \\ South Africa
}

\section{Abstract}

Unintended pregnancy (UIP) poses considerable humanistic and economic burden in both developed and developing countries. In the analysis described here, we evaluate the costs of unintended pregnancies based on estimates in South Africa. To estimate the burden of UIP, a decision-analytic model was developed using probabilities for pregnancy related outcomes related to UIPs in a single year, which included miscarriage, ectopic pregnancy, abortion and live birth. Costs to the public health system were estimated for each birth outcome. We estimated 636,040 annual unintended pregnancies. The annual maternal deaths were estimated to be 1134 of which 219 (19.3\%) are attributed to abortions and 915 (80.7\%) attributed to complications from miscarriages, ectopic pregnancies and deliveries. The costs attributed to UIP birth outcomes accounted for 3.42 billion Rand annually. Annual costs of UIP live births were estimated to be $82.8 \%$ of the total costs with abortion and miscarriage accountable for $8.3 \%$ and $8.4 \%$ of costs, respectively. In conclusion, despite weaknesses of modelling approaches in healthcare, we believe that our findings here will support further preventative initiatives in South Africa and more broadly to improve access to affordable and effective contraception.

\section{Introduction}

The concept of unintended pregnancies is multifactorial and broadly encompasses pregnancies that are either unwanted or mistimed. ${ }^{1}$ Obtaining specific estimates on unintended pregnancies is difficult due to data limitations and differences in classifying and reporting of pregnancies. Global estimates suggest there were 86 million unintended pregnancies in 2008 with 74 million (86\%) occurring in less developed countries. ${ }^{2}$

In many instances unintended pregnancies are likely to end by induced abortion where worldwide estimates suggest $50 \%$ will be voluntarily terminated. ${ }^{3}$ In 2008 it was estimated that 43.8 million abortions occurred worldwide of which $86 \%$ occurred in developing economies. ${ }^{4}$ Furthermore, between 2003 and 2008 the number of induced abortions was found to decrease in developed economies, but increased in developing economies. ${ }^{4}$ During this same period of time, the proportion of unsafe abortions increased and unsafe abortions were believed to account for $13 \%$ of maternal deaths, with the majority of them concentrated in countries with restrictive laws on abortion. ${ }^{5}$

The effects of unintended pregnancy can influence many facets of life and society. These can include impacts on physical and mental health status and reductions in quality of life. ${ }^{6,7}$ Children born from unintended pregnancies are also at risk of being born with low birth weight and premature birth compared with planned pregnancies. ${ }^{8,9}$ Furthermore, women with unintended pregnancies are thought to be at increased risk of physical abuse. ${ }^{10}$ The problem of unintended pregnancies can be additive as children born from an unintended pregnancy are also likely to perpetuate unintended pregnancies when they are adults. ${ }^{11,12}$

Many countries with abortion restrictions pose considerable personal harm and economic consequences to those that pursue illegal and unsafe abortions. Previous estimates suggest an average cost of treating post abortion complications range from $\$ 86$ - $\$ 111$ (2006). ${ }^{13}$ In Latin America and Africa alone the total health costs combined were $\$ 159$ million to $\$ 333$ million per year which represents a significant cost for these health services. ${ }^{13}$

South Africa faces a quadruple burden of disease. ${ }^{14}$ These include the colliding HIV and tuberculosis epidemics, a high burden of chronic illness, mental health disorders, injury and violence-related deaths, as well as a silent epidemic of maternal, neonatal, and child mortality. At present, the health system in South Africa has a predominantly curative focus which places less emphasis on disease prevention and health promotion. ${ }^{15}$ South Africa's per capita health burden is the highest of any middle-income country ( $8.7 \%$ of its GDP) in the world. ${ }^{14}$ A comprehensive National Department of Health (DoH) Strategic Plan 2010/20112012/13 was developed reflecting interventions to improve health service delivery and improve health outcome for all South Africans. ${ }^{15}$
Correspondence: Mark Connolly, Unit of Pharmacoeconomics and Pharmacoepidemiology, Department of Pharmacy, University of Groningen, Antonius Deusinglaan 1, 9713 AV Groningen, The Netherlands.

E-mail: m.connolly@rug.nl

Key words: Unintended pregnancy; Economic impact; South Africa.

Contributions: HHL, model development, literature review, results generation, manuscript development; MPC, review model design, input identification, critical review of results, manuscript development; JY, critical review model design, model input identification, manuscript review; YP, critical review model design, model input identification, manuscript review; PSS, critical review model design, clinical input identification, clinical interpretation, policy impact, manuscript development.

Conflict of interest: the research conducted by Dr. Mark Connolly was funded by an unrestricted grant from Merck (Whitehouse Station, NJ, USA). Dr. Jingbo Yu and Mr. Yacob Pinchevsky are employees of Merck. Professor Petrus Steyn, Dr. Hoa Le and Dr. Mark Connolly declare no conflict of interest regarding the publication of this article, and specifically no financial interests in the commercial operations of Merck.

Acknowledgements: we would like to thank Princess Makhosazane Majola for her inputs and assistance in data collection.

Received for publication: 29 April 2015

Revision received: 15 May 2015.

Accepted for publication: 16 May 2015.

This work is licensed under a Creative Commons Attribution 3.0 License (by-nc 3.0).

(C) Copyright H.H. Le et al., 2015

Licensee PAGEPress, Italy

Healthcare in Low-resource Settings 2015; 3:5258 doi:10.4081/hls.2015.5258

The objectives of this study were to evaluate the likely costs of UIP in South Africa using a deterministic modeling approach. As with all modelling approaches there are inherent weaknesses attributed to changing treatment practices, data limitations and evolving cultural norms. Despite these weaknesses, we believe a model to measure the economic impact of UIPs would support the new initiatives of prevention. ${ }^{15}$

\section{Materials and Methods}

\section{Model description}

A deterministic decision tree model was developed to estimate the humanistic and 
economic burden of unintended pregnancies in South Africa. The timeframe for the analysis was one year. However, outcomes of unintended pregnancies within the year were allowed to take their course. All pregnancies among women on contraception were assumed to be unintended pregnancies. The annual cases of unintended pregnancies among women of reproductive age in South Africa were estimated using distribution of contraceptive use across methods and the associated failure rates. Conversely, pregnancies from women not using contraceptives were assumed to be wanted pregnancies and were not considered in the current analysis which likely leads to an underestimate of UIPs as many women not using contraceptives can experience an UIP.

The major outcomes of unintended pregnancies evaluated in the model were induced abortion, miscarriage, ectopic pregnancy, and live birth (Figure 1). Maternal mortality and related costs were assessed for each of these outcomes. While the legalization of abortion through the Choice on Termination of Pregnancy Act in 1996 permitted more choices for women and couples, the proportion of unsafe abortion, as defined by WHO, remains high in South Africa. ${ }^{4}$ Because of differences in maternal health and associated costs, abortions were further characterized as safe or unsafe abortions. Birth outcomes were also separated between deliveries taking palace within and outside of health facilities. Additionally, a distinction was made between vaginal and cesarean deliveries. Outcomes and resulting costs for infants were also followed. These included stillbirths and infant survival and complications from term and pre-term deliveries. Complications included admission to neonatal care, hospitalization during the first year, and cerebral palsy.

\section{Data source and analysis}

\section{Unintended pregnancies}

The number of unintended pregnancies was estimated by applying the distribution of contraceptive use and associated failure rates to the population of reproductive age women in South Africa (Table 1). The model evaluates contraceptive methods that are currently in use in South Africa. These include male and female condoms, oral contraceptive pills, hormonal injections (e.g., Depot medroxyprogesterone acetate and Nur-Isterate), copper intrauterine device (IUD), and female and male sterilization. We assumed that women on these contraceptive methods represent the total population of contraceptive users in South Africa.

The number of women on each contraceptive method was estimated using market share data from the DoH applied to the total population of reproductive age women (15-49 years old) in South Africa in 2011. ${ }^{16}$ Unintended pregnancies for each method were calculated by multiplying the number of women using the contraceptive with the failure rate associated with typical use. ${ }^{17}$ Although the failure rates were obtained from the United States, there is a lack of published data on contraceptive failures in South Africa and these figures are accepted in the contraception guidelines in South Africa. ${ }^{18}$ Contraceptive failure rates represent unintended pregnancies per 100 women per year.

\section{Outcomes of unintended pregnancies}

The model evaluated four pregnancy outcomes. We assumed that $14.4 \%$ of all unintended pregnancies ended in induced abortion. This figure was derived from estimates of abortions (6.8\%) and unintended pregnancies (47.3\%) as percentages of all pregnancies. ${ }^{19,20}$ For miscarriage and ectopic pregnancies,

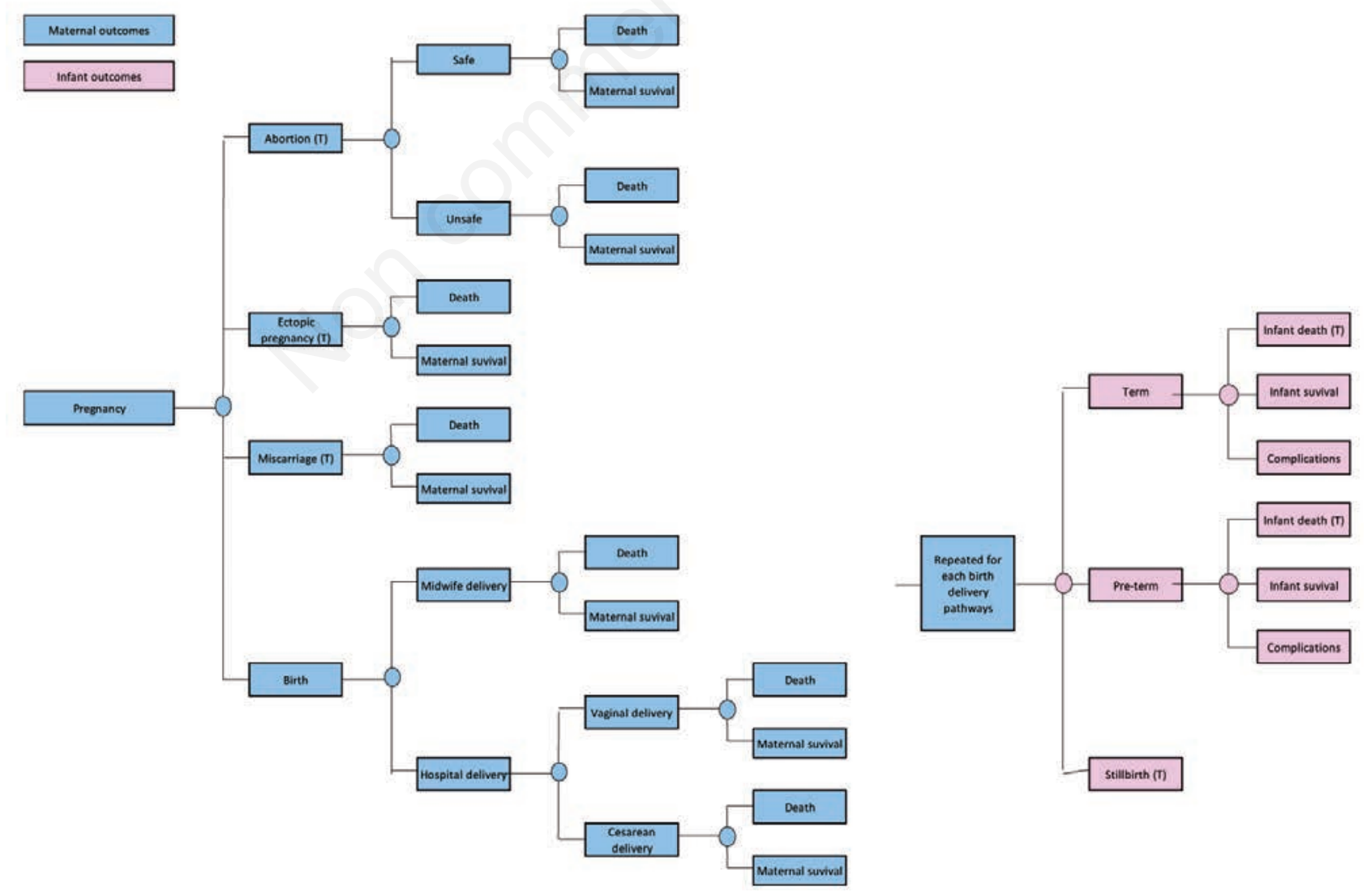

Figure 1. Model framework for assessing maternal and child burden and costs attributed to unintended pregnancies. 
$16.0 \%$ and $1.1 \%$ were used, respectively. ${ }^{21,22}$ Continuation to birth was assumed for the remainder of the unintended pregnancies.

We used data on unsafe abortion for Southern Africa as a proxy for South Africa. Because of the liberal laws on abortion in South Africa, the percentage of unsafe abortion in this region has dramatically decreased from $100 \%$ in 1995 to $58 \%$ in $2008 .{ }^{4}$ For the model, we assumed $58 \%$ unsafe and $42 \%$ safe abortion and mortality rates associated with each were 370 and 59 per 100,000 abortions, respectively.,23 Maternal mortality rates that were used for miscarriage, ectopic pregnancy, and birth were $6.73,2.72$, and 176.22 per 100,000 live births, respectively.

The vast majority $(90.1 \%)$ of deliveries were performed in a health facility of which $22.7 \%$ were cesarean deliveries. ${ }^{24,25}$ All deliveries outside of a health facility were assumed to be vaginal deliveries. Maternal mortality rate (MMR) of 176.22 per 100,000 deliveries was applied. ${ }^{26}$

The percentages of term, preterm, and stillbirths were $80.1 \%, 17.5 \%,{ }^{26}$ and $2.4 \%,{ }^{27}$ respectively, and were assumed to be independent of the place and type of deliveries. These infant outcomes and data on infant mortality and complications such as neonatal care admission, re-hospitalization, and cerebral palsy are summarized in Table 2.

\section{Cost of outcomes of unintended pregnancies}

Costs of subsequent outcomes of unintended pregnancies were only followed for abortion, miscarriage, ectopic pregnancies, and birth.
These estimates represent the average cost for each outcome. Miscarriage and ectopic pregnancies were assumed to incur the same cost. Itemized costing elements for each are provided in Table 3. The costs of contraceptive use prior to experiencing an UIP have been excluded, as these costs would not be incurred during the pregnancy period.

\section{Productivity loss due to unintended pregnancies}

An employment rate of $50 \%$ was used to estimate the number of women who were employed and had an unintended pregnancy. ${ }^{33}$ Based on statutory maternity leave benefits of 16 weeks, we estimated the broader economic consequences of UIP based on an average weekly salary for women of Rand (R) $643 .{ }^{34}$

Table 1. Distribution of contraceptive use and failure rates for estimating unintended pregnancy.

\begin{tabular}{lcccc} 
Contraceptives & $\begin{array}{c}\text { Population of women } \\
\text { (age } \mathbf{1 5 - 4 9} \text { years) }\end{array}$ & $\begin{array}{c}\text { Contraceptives } \\
(\%)\end{array}$ & $\begin{array}{c}\text { Women on } \\
\text { contraceptives (n) }\end{array}$ & $\begin{array}{c}\text { Failure per 100 } \\
\text { women per year (\%) }\end{array}$ \\
Condoms & $13,866,489$ & 8.1 & $1,125,437$ & 18.00 \\
Oral contraceptives & $13,866,489$ & 12.2 & $1,695,101$ & 202,579 \\
\hline Depot medroxyprogesterone acetate & $13,866,489$ & 19.0 & $2,634,633$ & 152,559 \\
Nur-isterate & $13,866,489$ & 13.8 & $1,913,575$ & 6.00 \\
IUD device & $13,866,489$ & 0.8 & 111,155 & 6.00 \\
Sterilization - female & $13,866,489$ & 10.1 & $1,403,322$ & 0.80 \\
\hline Sterilization - male & $13,866,489$ & 0.5 & 69,472 & 8.078 \\
Total & & 64.6 & $8,952,695$ & 0.50 \\
\hline
\end{tabular}

UIP, unintended pregnancy; IUD, intrauterine.

Table 2. Infant mortality and complications. ${ }^{28-32}$

\begin{tabular}{|c|c|c|}
\hline \multicolumn{2}{|c|}{ Vaginal deliveries } & $\mathbf{P}$ \\
\hline Term delivery* & $\begin{array}{l}\text { Infant mortality } \\
\text { Neonatal care admission }{ }^{\circ} \\
\text { Cerebral palsy } \\
\text { Intrapartum-related birth asphyxia }\end{array}$ & $\begin{array}{c}0.0427 \\
0.10 \\
0.0002 \\
0.0048\end{array}$ \\
\hline Preterm delivery & $\begin{array}{l}\text { Infant mortality } \\
\text { Neonatal care admission }{ }^{\circ} \\
\text { Cerebral palsy } \\
\text { Intrapartum-related birth asphyxia }\end{array}$ & $\begin{array}{c}0.1000 \\
1 \\
0.0002 \\
0.0048\end{array}$ \\
\hline Stillbirth & - & 0.0240 \\
\hline Cesarean deliv & & $\mathbf{P}$ \\
\hline Term delivery* & $\begin{array}{l}\text { Infant mortality } \\
\text { Neonatal care admission }{ }^{\circ} \\
\text { Cerebral palsy } \\
\text { Intrapartum-related birth asphyxia }\end{array}$ & $\begin{array}{c}0.0427 \\
0.10 \\
0.0018 \\
0.0048\end{array}$ \\
\hline Preterm delivery & $\begin{array}{l}\text { Infant mortality } \\
\text { Neonatal care admission } \\
\text { Cerebral palsy } \\
\text { Intrapartum-related birth asphyxia }\end{array}$ & $\begin{array}{c}0.1000 \\
1 \\
0.0018 \\
0.0048\end{array}$ \\
\hline Stillbirth & - & 0.0240 \\
\hline
\end{tabular}

*Derived from residual of preterm births. ${ }^{\circ}$ Information was obtained from staff working at the Neonatal Intensive Care Unit at Tygerberg Hospital in Stellenbosch University. Probabilities of term delivery and preterm delivery were in both cases 0.8010 and 0.1750 , respectively. 
Table 3. Itemized costs of abortion, miscarriage, ectopic pregnancies, and birth in public hospitals.

Abortion

Patient transport service - Facility Fee

286.00

$\begin{array}{lr}\text { Emergency consultation - Nursing practitioner } & 65.00\end{array}$

$\begin{array}{lr}\text { Emergency consultation - Nursing practitioner facility fee } & 136.00\end{array}$

$\begin{array}{lr}\text { Emergency consultation - General medical practitioner } & 113.00\end{array}$

Emergency consultation - General medical practitioner facility fee $\quad 136.00$

$\begin{array}{lr}\text { Pregnancy test } & 0.68\end{array}$

HIV test - rapid screen test $\quad 38.21$

If HIV test is positive

$\begin{array}{lr}\text { CD4 Helper T Cell Marker } & 19.28\end{array}$

$\begin{array}{ll}\text { HIV Western Blot } & 68.17\end{array}$

$\begin{array}{ll}\text { Viral load } & 36.19\end{array}$

Inpatient General Ward - Specialist medical practitioner (X3 days) 294.00

Inpatient General Ward - Specialist medical practitioner (X3 days) facility fee $\quad 819.00$

Minor Procedure Cat C -General medical practitioner $\quad 258.00$

Minor Procedure Cat C -General medical practitioner facility fee $\quad 319.00$

Radiology, Cat C - General medical practitioner $\quad 88.20$

$\begin{array}{lr}\text { Radiology, Cat C - General medical practitioner facility fee } & 137.40\end{array}$

$\begin{array}{ll}\text { Ultrasound gel } & 3.57\end{array}$

$\begin{array}{ll}\text { Mortuary - Facility Fee } & 138.00\end{array}$

$\begin{array}{lr}\text { Cremation Certificate - Facility Fee } & 138.00\end{array}$

Total

3093.69

\begin{tabular}{|c|c|c|}
\hline \multirow{19}{*}{$\begin{array}{l}\text { Miscarriage and } \\
\text { ectopic pregnancy }\end{array}$} & Patient transport service -Facility Fee & 286.00 \\
\hline & Emergency consultation - Nursing practitioner & 65.00 \\
\hline & Emergency consultation - Nursing practitioner facility fee & 136.00 \\
\hline & Emergency consultation - General medical practitioner & 113.00 \\
\hline & Emergency consultation - General medical practitioner facility fee & 136.00 \\
\hline & Pregnancy test & 0.68 \\
\hline & HIV test - rapid screen test & 38.21 \\
\hline & If HIV test is positive & \\
\hline & CD4 Helper T Cell Marker & 19.28 \\
\hline & HIV Western Blot & 68.17 \\
\hline & Viral load & 36.19 \\
\hline & Inpatient General Ward - Specialist medical practitioner (X3 days) & 294.00 \\
\hline & Inpatient General Ward - Specialist medical practitioner (X3 days) facility fee & 819.00 \\
\hline & Minor Procedure Cat C -General medical practitioner & 258.00 \\
\hline & Minor Procedure Cat C -General medical practitioner facility fee & 319.00 \\
\hline & Radiology, Cat C - General medical practitioner & 88.20 \\
\hline & Radiology, Cat C - General medical practitioner facility fee & 137.40 \\
\hline & Ultrasound gel & 3.57 \\
\hline & Total & 2817.69 \\
\hline \multirow[t]{22}{*}{ Birth } & Outpatient consultation - Nursing Practitioner & 43.00 \\
\hline & Outpatient consultation - Nursing Practitioner facility fee & 67.00 \\
\hline & Urine Dipstick - pregnancy & 3.40 \\
\hline & Urine Dipstick - glucose, protein, Nitrates etc. & 17.00 \\
\hline & Full blood count & 50.25 \\
\hline & HIV test - rapid screen test & 38.21 \\
\hline & If $\mathrm{HIV}$ test is positive & \\
\hline & CD4 Helper T Cell Marker & 19.28 \\
\hline & HIV Western Blot & 68.17 \\
\hline & Viral load & 36.19 \\
\hline & Inpatient General Ward - Medical practitioner & 98.00 \\
\hline & Inpatient General Ward - medical practitioner facility fee & 273.00 \\
\hline & Minor Procedure Cat B -General medical practitioner & 163.00 \\
\hline & Minor Procedure Cat B -General medical practitioner facility fee & 319.00 \\
\hline & Nurse Practitioner in ward & 37.00 \\
\hline & Nurse Practitioner in ward Facility Fee & 273.00 \\
\hline & Natural Birth - Nursing practitioner & 1944.00 \\
\hline & Neonatal Care Facility Fee & 2963.00 \\
\hline & Paracetamol - box of 10 to take home & 0.76 \\
\hline & Folic acid + ferrous sulphite (Vitaforce Ferovit) & 76.95 \\
\hline & Vaccination Neonate BCG R1.77 + Oral polio & 4.07 \\
\hline & Total & 6494.27 \\
\hline
\end{tabular}

[Healthcare in Low-resource Settings 2015; 3:5258] [page 27] 


\section{Results}

Based on reported annual births and probabilities for unintended pregnancies, miscarriage and induced abortion rates we estimated 636,040 annual unintended pregnancies. The annual maternal deaths were estimated to be 1134 of which 219 (19.3\%) were attributed to abortions and 915 (80.6\%) attributed to complications from miscarriages, ectopic pregnancies and deliveries (Table 4). The number of infant deaths attributed to unplanned pregnancies within 12-months following birth was estimated at 30,754 . We estimated 76,272 preterm deliveries attributed to unintended pregnancies. The estimated number of neonatal admissions associated with unintended pregnancies was estimated to be 100,175 that included all preterm deliveries and $7.6 \%$ of term deliveries.

Based on the estimated number of annual UIPs, we estimate annual cost to the public health system of R3.42 million. The majority of costs within the health service were attributed to live births from UIPs at cost of R2.83 million. The estimated costs of miscarriage and abortion for a single year were R287 million and R282 million, respectively. The estimated annual cost per UIP case based on each potential outcome is described in Table 5.

Of the predicted number of unintended pregnancies, we anticipated 45,720 and 217,919 employed women to be impacted from abortions and births, respectively. Based on the statutory maternity leave allowance for women, the costs were estimated to be R2.24 billion per annum.

\section{Discussion}

In many cases unintended pregnancies are partly due to lack of service provision and not meeting women's contraceptive needs. However, a large proportion of these pregnancies also occur due to lack of knowledge and myths regarding contraception, failure and discontinuation of short-term hormonal contraception. ${ }^{35}$

Contraceptive effectiveness is determined by several factors: efficacy (theoretical ability to prevent pregnancy), compliance, continuation, fecundity (ability to conceive) and timing of coitus. ${ }^{36}$ Combined oral contraceptives and barrier contraception are popular methods of contraception. However, their effectiveness is dependent on compliance and correct use. ${ }^{36,37}$ Efficacy can also be impaired because women commonly switch methods, often with a period of delay before starting the new method rendering them susceptible to unintended pregnancies. In this context, long acting reversible contraceptive (LARC) methods combine reversibility with high effectiveness and do not depend so much on compliance or correct use. The LARCs [except for depo medroxyprogesterone acetate (DMPA)] have higher continuation rates than other contraceptives such as the oral contraceptives and condoms. ${ }^{38}$

The results described here estimate an annual cost of R3.42 billion attributed to UIPs. From the total costs, UIPs that resulted in live birth represented $82.8 \%$ (R2.83 billion) of the total costs with abortion and miscarriage accountable for 8.3\% (R283 million) and 8.4\% (R287 million), respectively. These costs are likely to represent an underestimate, as we have not accounted for the costs attributed to neonatal admissions costs. Furthermore, preterm births are at risk of increased hospitalization in the early year of life, which would further increase the cost estimates described here. ${ }^{39}$

Expert opinion and supporting clinical guidelines indicated that the most effective approach to prevent unintended pregnancies is through education and contraceptive use, of which long-acting contraceptive methods are believed to be the most effective intervention. ${ }^{40-42}$ In particular, amongst adolescents, prevailing evidence suggests that education and contraception are the main interventions for reducing unintended pregnancies. ${ }^{42}$ Furthermore, previous economics analysis of providing reproductive services and contraception has been shown to be cost-saving compared with no contraception. A study in the United States estimated annual cost savings of $\$ 19.2$ billion attributed to pregnancies averted.$^{43}$ These costs are likely to be an underestimate as they do not consider long-term complications attributed to UIPs.

Previous studies have estimated the scale of unintended pregnancies in sub-Saharan Africa of approximately 42 million unintended births over a 5 -year time horizon. ${ }^{35}$ It was also estimated that approximately $44 \%$ of unintended births occurred in women under the age of 25 . The disproportionate amount of unintended births that occur in younger ages suggests our estimates of the indirect costs for maternity leave coverage are overestimated. In the absence of age-specific unintended pregnancies, we assumed a constant rate of UIPs, which may underestimate pregnancies in the younger ages.

Several policy options are available for reducing the burden of unintended pregnancies. Because of the high failure rates of oral

Table 4. Maternal and child outcomes attributed to unintended pregnancies.

\begin{tabular}{lc}
\hline Pregnancy (n) & 636,040 \\
Abortions (n) & 91,439 \\
\hline Ectopic pregnancies (n) & 6996 \\
Miscarriages (n) & 101,766 \\
\hline Births (n) & 435,838 \\
Maternal deaths (n) & \\
$\quad$ Abortion & 219 \\
Miscarriage & 7 \\
Ectopic pregnancy & 140 \\
Birth & 768 \\
Total & 1134 \\
\hline Preterm births (n) & 76,272 \\
Neonatal admissions ${ }^{\circ}$ (n) & 100,175 \\
\hline Cerebral palsy cases (n) & 749 \\
Infant deaths within the first year (n) & 32,754 \\
\hline oIt contains proportion of term births admitted. &
\end{tabular}

${ }^{\circ}$ It contains proportion of term births admitted.

Table 5. Annual costs and cost per case for different birth outcomes attributed to unintended pregnancies in South Africa.

\begin{tabular}{lccc} 
& Annual cost (Rand) & Cost (\%) & Cost per case (Rand) \\
Birth & 2830 million & 82.8 & 6494 \\
Miscarriage & 287 million & 8.4 & 2818 \\
\hline Ectopic pregnancy $^{\circ}$ & 20 million & 0.6 & 2818 \\
Abortion $^{\text {Total costs }}$ & 283 million & 8.3 & 3094 \\
\hline
\end{tabular}

${ }^{\circ}$ Costs for ectopic pregnancy are based on treatment practice for miscarriage. 
and injectable contraceptives, investigations have estimated the impact of switching to implants for those currently treated with alternative contraceptive methods. It was estimated that switching $1 \%$ of current contraceptive users to implants could avoid 18,600 UIPs per annum. A switch of 5\% current contraceptive use to implants could further reduce UIPs by 92,800 births annually, and the greater number switching to implants offered further reductions in UIPs. ${ }^{35}$

The inability to reliably estimate pregnancy intention is a weakness of the analysis described here. In the analysis described here, we attempted to evaluate unintended pregnancies based on contraceptive use and known failure rates for each method. Consequently, we assumed that any pregnancy that occurred while on contraceptives was an unintended pregnancy, which may not be the case with some pregnancies. Furthermore, by using contraceptive failure as a proxy for unintended pregnancy this does not account for women not using contraceptives that have unintended pregnancies. Because pregnancy intention cannot be assessed at the point of conception, and is often discussed post-conception, we believe that our estimates for unintended pregnancy are conservative.

An additional weaknesses of the analysis described here relates to the inclusion of mistimed pregnancies in the definition of unintended pregnancy. By definition, mistimed pregnancies are those that would likely have occurred at some point in the future. In this context the direct costs described here may overestimate costs in the short-term. However, mistimed pregnancies carry significant social and economic consequences that should not be accounted for in this analysis. These included reduced educational attainment for parents and a trend towards reduced education attainment of the impending child, ${ }^{44}$ and increased exposure to physical violence compared with intended pregnancies. ${ }^{45}$ Furthermore, mothers of mistimed pregnancies are less likely to consume prenatal care and consequently expose mother and child to preventable risks that will have cost implications at the time of delivery and beyond. ${ }^{45,46}$ To complicate matters there is considerable variation in the duration of mistimed pregnancies which could likely influence the negative consequences attributed to mistimed pregnancies that occur in older aged women. ${ }^{47}$

The synthesis of treatment outcomes and costs in economic models for health condition can help fill a void in the available evidence to inform future contraception policy. Whilst every effort is attempted to find precise cost estimates for each event, in many developing countries published cost estimates are not available on which to estimate treatment costs. In many instances it is necessary to apply estimates based on comparable resource items as we have done here. Without a reasonable estimate for ectopic pregnancy costs we have applied the cost of miscarriage to the ectopic pregnancy outcomes. Recognizing that ectopic pregnancies are likely more costly than miscarriages, this assumption likely underestimates the true costs. Furthermore, the authors acknowledge that in many instances data used for constructing the model was not current. This is a potential weakness, however considering there have been no major policy changes or introduction of new products during the years investigated. On this basis we believe that treatment practices have not changed substantially enough to undermine the model described here.

\section{Conclusions}

The analysis described here provides annual estimates for mortality and health service costs attributed to UIPs in South Africa. Despite weaknesses of modelling approaches in healthcare, we believe the findings here will support preventative initiatives in South Africa to improve access to affordable and effective contraception. In particular, initiatives that improve access to long-acting reversible contraceptives which have low failure rates and have been shown to be cost-effective. ${ }^{17,37}$

\section{References}

1. Santelli J, Rochat R, Hatfield-Timajchy K, et al. The measurement and meaning of unintended pregnancy. Perspect Sex Repro H 2003;35:94-101.

2. Singh S, Sedgh G, Hussain R. Unintended pregnancy: worldwide levels, trends, and outcomes. Stud Family Plann 2010;41: 241-50.

3. Gipson JD, Koenig MA, Hindin MJ. The effects of unintended pregnancy on infant, child, and parental health: a review of the literature. Stud Family Plann 2008;39:18-38.

4. Sedgh G, Singh S, Shah IH, et al. Induced abortion: incidence and trends worldwide from 1995 to 2008. Lancet 2012;379:625-32.

5. World Health Organization. Unsafe abortion incidence and mortality. Global and regional levels in 2008 and trends during 1990-2008. Geneva, Switzeralnd: World Health Organization; 2012 http://apps.who. int/iris/bitstream/10665/75173/1/WHO_RH R_12.01_eng.pdf

6. Khajehpour M, Simbar M, Jannesari S, et al. Health status of women with intended and unintended pregnancies. Public Health 2013;127:58-64.

7. Schwarz EB, Smith R, Steinauer J, et al.
Measuring the effects of unintended pregnancy on women's quality of life. Contraception 2008;78:204-10.

8. Eggleston E, Tsui A0, Kotelchuck M. Unintended pregnancy and low birth weight in Ecuador. Am J Public Health 2001;91:808-10.

9. Mohllajee AP, Curtis KM, Morrow B, Marchbanks PA. Pregnancy intention and its relationship to birth and maternal outcomes. Obstet Gynecol 2007;109:678-86.

10. Goodwin MM, Gazmararian JA, Johnson $\mathrm{CH}$, et al. Pregnancy intendedness and physical abuse around the time of pregnancy: findings from the pregnancy risk assessment monitoring system, 19961997. Matern Child Health J 2000;4:85-92.

11. Ferraro AA, Cardoso VC, Barbosa AP, et al. Childbearing in adolescence: intergenerational dejà-vu? Evidence from a Brazilian birth cohort. BMC Pregnancy Childbirth 2013;13:149.

12. de Almeida Mda C, Aquino EM. The role of education level in the intergenerational pattern of adolescent pregnancy in Brazil. Perspect Sex Repro H 2009;35:139-46.

13. Vlassoff M, Walker D, Shearer J, et al. Estimates of health care system costs of unsafe abortion in Africa and Latin America. Int Perspect Sex Reprod Health 2009;35:114-21.

14. Kleinert S, Horton R. South Africa's health: departing for a better future? Lancet 2009;374:759-60.

15. National Department of Health. National department of health strategic plan. Pretoria, South Africa: National Department of Health; 2010. Available from: http://www.mm3admin.co.za/documents/docmanager/2D5ED792-878C-43719575-8281A96BBB26/00023294.pdf

16. Statistics South Africa. Mid-year population estimates 2011. Pretoria, South Africa: Statistics South Africa; 2011. Available from: http://www.statssa.gov.za/ publications/P0302/P03022011.pdf

17. Trussell J. Contraceptive failure in the United States. Contraception 2011;83: 397-404.

18. Department of Health, Republic of South Africa. National contraception clinical guidelines. Pretoria, South Africa: Department of Health; 2012.

19. Johnston's Archive. Historical abortion statistics, South Africa, 2010. Available from: http://www.johnstonsarchive.net/ policy/abortion/ab-southafrica.html

20. South Africa demographic and health survey 2003. Available from: http://www.mrc. ac.za//bod/sadhs2003part2.pdf

21. Grobler F. Contraception, theory and practice. 4th ed. Preotria, South Africa: Van Schaik; 2003.

22. Amoko DH, Buga GA. Clinical presentation 
of ectopic pregnancy in Transkei, South Africa. East Afr Med J 1995;72:770-3.

23. Benson J, Andersen K, Samandari G. Reductions in abortion-related mortality following policy reform: evidence from Romania, South Africa and Bangladesh. Reprod Health 2011;8:39.

24. Health Systems Trust. Delivery rate in facility. Available from: http://indicators. hst.org.za/healthstats/229/data

25. Health Systems Trust. Caesarean section rate. Available from: http://indicators. hst.org.za/healthstats/76/data

26. Department of Health, National Committee for Confidential Enquiry into Maternal Deaths. Saving mothers 2008-2010. Fifth report on the confidential enquiries into maternal deaths in South Africa. 2012. Available from: http:/www.hst.org.za/publications/saving-mothers-2008-2010-fifthreport-confidential-enquiries-maternaldeaths-south-afri

27. Beck S, Wojdyla D, Say L, et al. The worldwide incidence of preterm birth: a systematic review of maternal mortality and morbidity. Bull World Health Organ 2010; 88:31-8.

28. National Perinatal Mortality And Morbidity Committee. Triennial report (2008-2010). Pretoria, South Africa: National Perinatal Mortality And Morbidity Committee; 2011.

29. Index Mundi. Infant mortality rate in South Africa 2012. Available from: http://www. indexmundi.com/g/g.aspx? $\mathrm{c}=\mathrm{sf} \& \mathrm{v}=29$

30. Drumbill D. Fit pregnancy. Available from: http:/www.birthoptions.co.za/dumbrill.html

31. Buchmann EJ, Pattinson RC, Nyathikazi $\mathrm{N}$. Intrapartum-related birth asphyxia in South Africa--lessons from the first national perinatal care survey. S Afr Med J 2002;92:897-901.

32. Health 24. Preterm birth an African killer. Available from: http:/www.health24.com/ news/Child_safety/1-943,77936.asp

33. Klaveren M, Tijdens K, Hughie-Williams M, Martin NR. An overview of women's work and employment in South Africa. Amsterdam, The Netherlands: University of Amsterdam; 2009. Available from: http://www.uva-aias.net/uploaded_ files/publications/WP79-Klaveren,Tijdens, Hughie-Williams,Ramos-SouthAfrica.pdf

34. Statistics South Africa. Monthly earnings of South Africans. Pretoria, South Africa: Statistics South Africa; 2010. Available from: http://www.statssa.gov.za/publications/P02112/P021122010.pdf

35. Hubacher D, Mavranezouli I, McGinn E. Unintended pregnancy in sub-Saharan Africa: magnitude of the problem and potential role of contraceptive implants to alleviate it. Contraception 2008;78:73-8.

36. Grimes DA. Commentary: forgettable contraception. Contraception 2009;80:497-99.

37. National Institute for Health and Clinical Excellence. Long-acting reversible contraception. Clinical Guideline 30. London: NICE; 2005. Available from: www.nice.org .uk/nicemedia/pdf/cg030niceguideline.pdf

38. Trussell J. Contraceptive efficacy. In: Hatcher RA, Trussell J, Nelson AL, Cates Jr W, Stewart F, Kowal D, eds. Contraceptive technology. 19th ed. New York, NY: Ardent Media Inc.; 2007. pp 747-826.

39. Petrou S. The economic consequences of preterm birth during the first 10 years of life. Brit J Obstet Gynaec 2005;112 (Suppl.1):10-5.
40. American College of Obstetricians and Gynecologists, Committee on Adolescent Health Care Long-Acting Reversible Contraception Working Group. Committee opinion no. 539: adolescents and long-acting reversible contraception: implants and intrauterine devices. Obstet Gynecol 2012;120:983-8.

41. Winner B, Peipert JF, Zhao 0, et al. Effectiveness of long-acting reversible contraception. New Engl J Med 2012;366: 1998-2007.

42. Oringanje C, Meremikwu MM, Eko H, et al. Interventions for preventing unintended pregnancies among adolescents. Cochrane Db Syst Rev 2009;4:CD005215.

43. Trussell J. The cost of unintended pregnancy in the United States. Contraception 2007;75:168-70.

44. Myhrman A, Olsén P, Rantakallio P, Läärä E. Does the wantedness of a pregnancy predict a child's educational attainment? Fam Plann Perspect 1995;27:116-9.

45. Gazmararian JA, Adams MM, Saltzman LE, et al. The relationship between pregnancy intendedness and physical violence in mothers of newborns. Obstet Gynecol 1995;85:1031-8.

46. Cheng D, Schwarz EB, Douglas E, Horon I. Unintended pregnancy and associated maternal preconception, prenatal and postpartum behaviors. Contraception 2009; 79:194-8.

47. Pulley L, Klerman LV, Tang H, Baker BA. The extent of pregnancy mistiming and its association with maternal characteristics and behaviors and pregnancy outcomes. Perspect Sex Repro H 2002;34:206-11. 